\title{
Improved hole injection/extraction using PEDOT:PSS interlayer coated onto high temperature annealed ITO electrode for efficient device performances
}

\section{Gnyaneshwar Dasi}

National Institute of Technology Warangal

Thyda Lavanya

National Institute of Technology Warangal

Govindasamy Sathiyan

Indian Institute of Technology Kanpur

\section{Raju Kumar Gupta}

Indian Institute of Technology Kanpur

\section{Ashish Garg}

Indian Institute of Technology Kanpur

\section{P. Amaladass}

Loyola Academy Degree and Post Graduate College

THANGARAJU KUPPUSAMY ( $\nabla$ ktr@nitw.ac.in )

National Institute of Technology Warangal https://orcid.org/0000-0002-3956-3260

\section{Research Article}

Keywords: ITO anodic electrode, High temperature annealing, PEDOT:PSS interlayer, Higher hole current density, organic photovoltaic cells, Improved device efficiency

Posted Date: March 11th, 2021

DOl: https://doi.org/10.21203/rs.3.rs-298362/v1

License: (c) (1) This work is licensed under a Creative Commons Attribution 4.0 International License. Read Full License 


\section{Abstract}

We demonstrate the improved device performances by using the structure of poly(3,4ethylenedioxythiophene):poly(styrene sulfonate) (PEDOT:PSS) film coated onto the indium tin oxide (ITO) anodic electrode annealed at $400{ }^{\circ} \mathrm{C}$ under the normal ambient. The ITO thin films show the improved film quality with decreased dislocation density and lattice strain as annealing temperature increases. The spincoated PEDOT:PSS film smoothens the wrinkle kind of surface morphology of the ITO film annealed at $400{ }^{\circ} \mathrm{C}$. The annealed ITO $\left(400^{\circ} \mathrm{C}\right)$ with PEDOT:PSS interlayer improves the hole-current density in the hole-only devices (HODs) having the device structure of ITO/PEDOT:PSS/N,N'-Bis(3-methylphenyl)-N,N'diphenylbenzidine as hole-transporting layer/Al. It enhances the efficiency of organic photovoltaic devices [ITO (annealed) /PEDOT:PSS/P3HT:PCBM (active layer)/LiF/Al] by three times higher (1.69 \%) when compared to that $(0.48 \%)$ of pristine ITO based OPV device. These results show that the annealing of ITO film at the high temperature of $400^{\circ} \mathrm{C}$ under the normal ambient improves the film quality and lowers the potential energy barrier at ITO/PEDOT:PSS interface for effective hole injection/extraction process, resulting in the enhanced device electrical performances.

\section{Introduction}

The recent technological developments and commercial applications of organic optoelectronic devices such as organic light emitting diodes (OLEDs) and organic photovoltaic cells (OPVs) have sparked wide research interest in order to improve the device efficiency and device durability for their potential use in the next generation flat panel displays, solid state lighting, and renewable solar energy harvesting owing to its ease of large area device fabrication by roll-to-roll printing, light weight, the possibility to fabricate flexible device, and cost effectiveness [1-11]. One of the several factors affecting the higher device efficiency and causing the failure of organic optoelectronic devices after continuous operation is the surface quality and/or bulk properties of indium tin oxide (ITO) film (anodic electrode) [12-14]. ITO is the n-type transparent conducting oxide (TCO) material most commonly used as thin anodic electrode in various electronic and/or optoelectronic devices such as transparent coatings for solar energy heat mirrors, liquid crystal flat-panel displays, OLEDs, OPVs, photo-transistors, and lasers, due to its excellent surface adherence, hardness, chemical inertness, wide band gap, higher transparency in the visible region, good electrical conductivity, high infrared reflectance, and tunable high work function [8-15]. The as-deposited ITO film is found to be less efficient for hole injection in OLEDs and hole collection or extraction process in the OPVs [16].

Since the ITO film is in direct contact with the organic thin film in the devices, the surface properties of ITO anodic electrode directly affect the hole injection/extraction process at ITO/organic interface and electrical properties of the devices $[17,18]$. Thus, the surface of ITO anode substrate has been modified by various methods such as chemical (Aquaregia, RCA), plasma $\left(\mathrm{O}_{2}, \mathrm{Ar}, \mathrm{H}_{2}\right)$, and UV-ozone treatments in order to improve the device efficiencies $[14,19,20]$.The post-deposition thermal annealing of ITO films prepared by various techniques such as direct current (dc) and radio frequency (rf) magnetron sputtering, electron beam evaporation, pulse laser method, spray pyrolysis, and the sol-gel method, has exhibited 
improved structural, optical and electrical properties. Maurya et al. has studied the post-thermal treatment of rf reactive sputtered ITO films and reported the improved crystalline structure with minimum resistivity of $8.3 \times 10^{-4} \Omega \mathrm{cm}$ and higher transparency of $90 \%$ in the visible region for the films annealed at $400{ }^{\circ} \mathrm{C}$ [21]. Cho et al. have reported that the as-deposited amorphous ITO film prepared by electron beam evaporation system exhibited the crystalline structure with lower sheet resistance and higher transmittance over $85 \%$ in the visible region after post-annealing at $300^{\circ} \mathrm{C}$ in an oxygen environment [22]. In contrary, the post-annealing (under the normal ambient, air) of if magnetron sputtered ITO thin films caused slight increase of resistivity upto $250^{\circ} \mathrm{C}$ which is attributed to free electron scattering by inoized impurities, whereas the resistivity abruptly increased above $250^{\circ} \mathrm{C}$ because of the change in the free electron scattering mechanism by chemisorbed oxygen atoms adsorbed at grain boundaries [23].

In support of the above results, our earlier studies on ITO substrates annealed at different temperatures under the normal ambient revealed that as annealing temperature increases upto $300^{\circ} \mathrm{C}$, the ITO film quality improves with slight increase in the sheet resistance ( $92 \Omega / €$ for pristine and $105 \Omega / €$ for $300^{\circ} \mathrm{C}$ ), enhancing the hole injection properties at the ITO/organic interface in hole-only devices, whereas the annealing of ITO at $400^{\circ} \mathrm{C}$ forms the wrinkle kind of surface morphology with higher sheet resistance of $185 \Omega / €$, limiting the hole current through the interface in the device [24]. These reports show that the film quality (bulk), surface chemical and morphological properties of ITO thin film are the important parameters to make it more efficient to be used as anodic electrode in the optoelectronic devices. In the recent years, a polymer poly(3,4-ethylenedioxythiophene):poly(styrene sulfonate)(PEDOT:PSS) has been most extensively studied for their wide use in conductive layers, capacitors, antistatic coatings, and organic optoelectronic devices due to its high conductivity, high transparency, easy film deposition, and mechanical flexibility [25-27]. When the solution processed PEDOT:PSS layer is introduced in light emitting diodes and organic solar cells as buffer layer, it facilitates the hole transport and hole injection/extraction process at the interface, thus enhancing the efficiency and lifetime of the devices [28, 29].

In this report, we study the optical, structural, and morphological properties of the bilayer structure of PEDOT:PSS film coated onto pristine and annealed $\left(200,300,400^{\circ} \mathrm{C}\right)$ ITO films using various techniques such as X-ray diffraction (XRD), UV-visible transmittance, scanning electron microscopy (SEM), and fourprobe method. We fabricate the hole-only devices (HODs) based on PEDOT:PSS coated pristine or annealed ITO film (anodic electrode) to study the hole injection/extraction characteristics of the structure in the devices. This bilayer structure is also utilized in the OPVs for the improved device performances.

\section{Experimental Details}

ITO coated glass substrates (TECHINSTRO, ITO-TIX005) with the thickness of $\sim 200 \mathrm{~nm}$ were cut into $2 \times 2$ $\mathrm{cm}^{2}$ area and were annealed at 200,300 , and $400^{\circ} \mathrm{C}$ in the tubular furnace under the normal ambient for 1 hour. The pristine and annealed ITO films were rinsed and ultrasonically cleaned in soap solution, deionized water, acetone, isopropyl alcohol (IPA) and finally in deionized water for 10 minutes, and dried for 10 minutes at $120^{\circ} \mathrm{C}$ in each step using vacuum oven to evaporate the solvents used, fingerprints and 
other oil contaminations on the ITO surface. These ITO substrates were cleaned using plasma cleaner (Harrick Plasma, PDC-002) under the ambient pressure of 800 micron for 10 min to remove the unwanted ions on the ITO surface and followed by UV light treatment for 10 minutes under the normal ambient using UV light curing system (Kaivo, UV-1318) to increase the work function and/or adherence of ITO films. The PEDOT:PSS solution (Sigma-Aldrich, Catalog No.: 739316 ) was filtered using $0.45 \mu \mathrm{m}$ syringe filter and spin-coated onto the cleaned pristine and annealed ITO films at $5500 \mathrm{rpm}$ for 60 seconds using programmable spin-coating unit (Apex Instruments, spinNXG-P2 model) and dried at $120^{\circ} \mathrm{C}$ for 10 minutes. The thickness of spin-coated PEDOT:PSS film was measured to be around $45 \mathrm{~nm}$ using stylus profilometer (Bruker's DektakXT stylus). The optical transmittance spectra of the bilayer structure of PEDOT:PSS film coated onto the pristine and annealed ITO films were measured using ultraviolet -visible (UV-vis) spectroscopic technique (Agilent, Carry 5000). The measurements of sheet resistance of the bilayer structure were carried out using the current/voltage source/measure unit (Keithley SMU, 2450 model) by four-point collinear probe method at room temperature. The X-ray diffraction spectra were recorded using XRD (PANanalytical Netherlands, XPERT-PRO model) with Cu K-alpha (X-ray source) radiation (wavelength $(\lambda)$ of $1.5406 \AA$ ). The surface morphological studies were carried out using SEM (TESCAN, VEGA3LMU model).

\subsection{Fabrication of Hole-Only devices (HODs)}

The pristine and annealed $\left(200,300\right.$, and $\left.400^{\circ} \mathrm{C}\right)$ ITO films were patterned for the device area of $4 \mathrm{~mm}^{2}$ by chemical etching process using hydrochloric acid $(\mathrm{HCl})$ and zinc dust, and thoroughly cleaned by the above substrate cleaning procedure. The Hole-only devices (HODs) were fabricated with the device structure: Pristine or annealed $\left(200,300,400^{\circ} \mathrm{C}\right)$ ITO substrate (anodic electrode)/PEDOT:PSS as hole injection layer (HIL) (45 nm)/N,N-Bis(3-methylphenyl)- $N, N$-diphenylbenzidine (TPD) (Sigma-Aldrich, Catalog No.: 443263) as hole transport layer (HTL) $(60 \mathrm{~nm}) / \mathrm{Al}$ as cathode $(120 \mathrm{~nm})$. The TPD HTL and Al electrode were deposited using organic and metal mask for the device area of $4 \mathrm{~mm}^{2}$ by thermal evaporation unit under the vacuum of $\sim 6 \times 10^{-6}$ Torr. The current density - voltage $(J-V)$ characteristics of the fabricated HODs were measured using the voltage/current source/measure unit (Keithley SMU, 2450 model) under the normal ambient.

\subsection{Fabrication of Organic Photovoltaic Cells (OPVs)}

The $15 \mathrm{mg} / \mathrm{mL}$ of P3HT and PCBM each with the volume ratio of 1:1 were dissolved in chlorobenzene solvent and stirred at $600 \mathrm{rpm}$ at $50^{\circ} \mathrm{C}$ in glove box under the $\mathrm{N}_{2}$ ambient for 12 hours followed by filtration using $0.45 \mu \mathrm{m}$ syringe filter (Solution A). The PEDOT:PSS solution filtered using $0.45 \mu \mathrm{m}$ syringe filter (Solution B) was spin-coated onto the cleaned pristine or annealed ITO films as a buffer layer at $5500 \mathrm{rpm}$ for $60 \mathrm{sec}$ and dried at $120^{\circ} \mathrm{C}$ for 10 minutes on hot plate. The P3HT:PCBM (active) layer was spin-coated using solution A onto the PEDOT:PSS layer at $800 \mathrm{rpm}$ for $60 \mathrm{sec}$ and dried at $150^{\circ} \mathrm{C}$ for 10 minutes on hot plate. Lithium fluoride (LiF) as electron injection layer (EIL) and aluminum (Al) as cathodic electrode were deposited using metal mask for the device area of $4 \mathrm{~mm}^{2}$ by thermal evaporation process at $\sim 5 \times 10^{-6}$ Torr. The structure of fabricated OPVs is of ITO (pristine or annealed at 200, 300, 
$\left.400^{\circ} \mathrm{C}\right) / \mathrm{PEDOT}: \mathrm{PSS}(45 \mathrm{~nm}) / \mathrm{P} 3 \mathrm{HT}: \mathrm{PCBM}(100 \mathrm{~nm}) / \mathrm{LiF}(1 \mathrm{~nm}) / \mathrm{Al}(120 \mathrm{~nm})$. The fabricated OPVs were characterized using current/voltage source measurement unit (Keithley's SMU unit, 2450 model) and the photocurrent was measured under AM 1.5 solar simulator source of $100 \mathrm{~mW} / \mathrm{cm}^{2}$.

\section{Results And Discussion}

The bilayer structure of PEDOT:PSS layer spin-coated onto the pristine and annealed (200, 300, and $400^{\circ} \mathrm{C}$ ) ITO films is characterized by using various studies. Figure 1 shows the optical transmittance spectra of PEDOT:PSS coated pristine and annealed $\left(200,300\right.$, and $\left.400^{\circ} \mathrm{C}\right)$ ITO films. It is observed that the PEDOT:PSS/pristine ITO bilayer structure is having good transparency ( $96 \%$ at $550 \mathrm{~nm}$ ) in the visible region without any significant change for increasing annealing temperature of ITO film ( $95 \%$ for $200^{\circ} \mathrm{C}$ and $96 \%$ for $300^{\circ} \mathrm{C}$ at $550 \mathrm{~nm}$ ). It has been reported that annealing the bare ITO film under the normal ambient forms the light absorbing/scattering centers in the film and slightly decreases the transparency in the visible region [24]. The transmittance of PEDOT:PSS/annealed $\left(400^{\circ} \mathrm{C}\right)$ ITO bilayer structure is considerably decreased in the UV region ( $33 \%$ at $325 \mathrm{~nm}$ ) when compared to other films ( $58 \%$ for pristine, $61 \%$ for $200^{\circ} \mathrm{C}$ and $57 \%$ for $300^{\circ} \mathrm{C}$ at $325 \mathrm{~nm}$ ) without any significant change in its transmittance in the visible region $\left(97 \%\right.$ for $400^{\circ} \mathrm{C}$ at $550 \mathrm{~nm}$ ), which may be attributed to the significant change in the ITO film and/or in the ITO/PEDOT:PSS interface properties upon annealing of ITO at high temperature of $400^{\circ} \mathrm{C}[23,24]$.

The direct optical bandgap energy $\left(\mathrm{E}_{\mathrm{g}}\right)$ of PEDOT:PSS/pristine or annealed ITO bilayer structure is determined from transmittance spectra using the following formula.

$(a h u)^{2}=A\left(h u-E_{g}\right)$

Where, $a(a=2.303(1 / T) / t, T$ - transmittance, $t$ - total film thickness) is the absorption coefficient, hu is the photon energy, and $A$ is the constant. The inset of Fig. 1 shows the plot of (ahu) ${ }^{2}$ versus hu, and the optical band gap $\left(E_{g}\right)$ energies were obtained by extrapolating the linear portion of $(a h u)^{2}$ against to the photon energy (hu) where the absorption coefficient (a) is equal to zero. The PEDOT:PSS coated pristine ITO film exhibited the band gap energy $\left(E_{g}\right)$ of $3.75 \mathrm{eV}$ which is consistent with the reported values [24]. No significant change in the optical band gap $\left(3.73 \mathrm{eV}\right.$ for $200^{\circ} \mathrm{C}$ and $3.67 \mathrm{eV}$ for $\left.300^{\circ} \mathrm{C}\right)$ is observed for annealing of ITO film upto $300^{\circ} \mathrm{C}$ in the bilayer structure and the similar trend has been reported in the case of bare annealed ITO film below $300^{\circ} \mathrm{C}$ [24]. The PEDOT:PSS/annealed $\left(400^{\circ} \mathrm{C}\right)$ ITO bilayer structure showed a slight decrease in the optical band gap ( $3.43 \mathrm{eV})$, attributed to the quantum confinement effect due to increase in crystallite size upon annealing $[24,30]$.

The XRD patterns of PEDOT:PSS/pristine or annealed $\left(200,300\right.$, and $\left.400^{\circ} \mathrm{C}\right)$ ITO bilayer structure are obtained at room temperature and shown in the Fig. 2. The PEDOT:PSS/pristine ITO bilayer exhibits the diffraction peaks corresponding to ITO [2 $\theta$ (corresponding hkl plane): $21.39^{\circ}(211), 30.35^{\circ}(222), 35.28^{\circ}$ (400), $50.60^{\circ}(440)$, and $60.19^{\circ}$ (622), consistent with the JCPDS data (Card No.: 39-1058)], showing the good crystalline properties of ITO film. The PEDOT:PSS/annealed ITO bilayer showed the similar 
diffraction pattern without any change in the peak positions with increased diffraction peak intensities for increasing annealing temperature of ITO film. The crystallite size of PEDOT:PSS/pristine or annealed $\left(200,300\right.$, and $\left.400^{\circ} \mathrm{C}\right)$ ITO bilayer has been calculated using Debye-Sherrer's formula.

$D=0.94 \lambda / \beta \cos \theta$

Where $D$ is the crystallite size, $\lambda$ is the X-ray wavelength (1.5046 $\AA$ ), $\beta$ is the full width half maxima and $\theta$ is the diffraction angle. It is observed that the average crystallite size is increasing as annealing temperature of ITO film in the bilayer increases (Fig. 3), which is attributed to combining of native crystalline grains into large size upon annealing under the normal ambient and resulting in the improved ITO film quality [24].

The dislocation density $(\delta)$ is defined as the length of dislocation lines per unit volume of the crystal. It is calculated for PEDOT:PSS/pristine or annealed $\left(200,300\right.$, and $\left.400^{\circ} \mathrm{C}\right)$ ITO bilayer using the following equation [31]. The estimated values are given in Table 1 and shown in Fig. 4.

Table 1

The optical, electrical, and crystalline parameters of the PEDOT:PSS layer coated pristine and annealed ITO films

\begin{tabular}{|c|c|c|c|c|c|c|c|c|}
\hline \multirow[t]{3}{*}{ Film } & \multirow{2}{*}{\multicolumn{2}{|c|}{$\begin{array}{l}\text { Optical } \\
\text { Transmittance } \\
\text { (\%) @ }\end{array}$}} & \multirow{3}{*}{$\begin{array}{l}\text { Optical } \\
\text { band } \\
\text { gap } \\
\text { energy } \\
\text { (Eg) } \\
\text { (eV) }\end{array}$} & \multirow{3}{*}{$\begin{array}{l}\text { Average } \\
\text { Crystallite } \\
\text { size } \\
(\mathrm{nm})\end{array}$} & \multirow{3}{*}{$\begin{array}{l}\text { Dislocation } \\
\text { density } \\
\left(\times 10^{14}\right. \\
\left.\text { lines } / \mathrm{m}^{2}\right)\end{array}$} & \multirow{3}{*}{$\begin{array}{l}\text { Lattice } \\
\text { Strain } \\
\left(\times 10^{-}\right. \\
2) \\
\text { (no } \\
\text { unit) }\end{array}$} & \multirow{2}{*}{\multicolumn{2}{|c|}{$\begin{array}{l}\text { Sheet } \\
\text { Resistance }(\Omega / \bigotimes)\end{array}$}} \\
\hline & & & & & & & & \\
\hline & $\begin{array}{l}325 \\
\mathrm{~nm}\end{array}$ & $\begin{array}{l}550 \\
\mathrm{~nm}\end{array}$ & & & & & ITO & ITO/PEDOT:PSS \\
\hline Pristine & 58 & 96 & 3.75 & 21.01 & 25.06 & 0.54 & 8.3 & 8.0 \\
\hline $200^{\circ} \mathrm{C}$ & 61 & 95 & 3.73 & 22.72 & 22.90 & 0.51 & 8.4 & 8.1 \\
\hline $300^{\circ} \mathrm{C}$ & 57 & 96 & 3.67 & 24.26 & 19.43 & 0.47 & 8.9 & 8.3 \\
\hline $400^{\circ} \mathrm{C}$ & 33 & 97 & 3.43 & 26.07 & 17.33 & 0.44 & 30.8 & 23.56 \\
\hline
\end{tabular}

$\delta=n / D^{2}$

Where $\delta$ is the dislocation density, $\mathrm{n}$ (= 1 for minimum dislocation density) is the factor, and $\mathrm{D}$ is the crystallite size. The strain induced in the lattice sites due to the lattice mismatch in the crystalline material is called as lattice strain $(\varepsilon)$ and it is estimated from the Williamson-Hall equation [32].

$\varepsilon=\beta_{\mathrm{hkl}} / 4 \tan \theta$

Where $\varepsilon$ is the lattice strain, $\beta$ is the FWHM, $\theta$ is the diffraction angle. From the Fig. 4 , the trend of decreasing lattice strain with increase of annealing temperature of ITO film in the bilayer structure is attributed to the observed decrease of dislocation density contributed by decreasing of grain boundaries due to growing crystallites [33, 34]. 
Figure 5 shows the SEM morphological images of PEDOT:PSS film coated pristine or annealed $(200,300$, and $400^{\circ} \mathrm{C}$ ) ITO bilayer structure in comparison with that of bare pristine or annealed ITO film, respectively. It is observed that the surface morphology of spin-coated PEDOT:PSS film coated onto pristine or annealed $\left(200\right.$ and $\left.300^{\circ} \mathrm{C}\right)$ ITO film is smooth and uniform as similar to that of bare pristine or annealed ITO films. The bare ITO film annealed at higher temperature $\left(400^{\circ} \mathrm{C}\right)$ exhibited the wrinkle kind of surface morphological features, which may be attributed to the bending and contraction of skeletal network caused by large amount of stress induced in the film during annealing [24,35]. Interestingly, the spin-coating of PEDOT:PSS film onto the wrinkle surface leads to the smooth and uniform surface morphology of the bilayer structure with increased PEDOT:PSS/ITO interfacial surface area.

The sheet resistance $\left(R_{S}\right)$ values of PEDOT:PSS coated pristine or annealed ITO bilayer and pristine or annealed ITO films have been estimated using the collinear four-probe technique with the relation

$\mathrm{R}_{\mathrm{s}}=[\pi / \ln \cdot 2] \cdot(\mathrm{V} / \mathrm{I}) \cdot k$

Where $\mathrm{I}$ is the current measured between the probes 1 and $4, \mathrm{~V}$ is the voltage measured between the probes 2 and 3 , and $k(=1)$ is the correction factor. The observed higher sheet resistance of $30.86 \Omega / \nabla$ for ITO film annealed at $400^{\circ} \mathrm{C}$ with slight increase upto $300^{\circ} \mathrm{C}(8.3 \Omega / \otimes$ for Pristine ITO film, $8.4 \Omega / \otimes$ for $200^{\circ} \mathrm{C}, 8.9 \Omega / \otimes$ for $300^{\circ} \mathrm{C}$ ) is consistent with the earlier report and attributed to a significant change in the grain boundaries and/or surface morphology of the films upon annealing at higher temperature [24]. The coating of PEDOT:PSS film onto the pristine or annealed ITO films shows no significant decrease in the sheet resistance upto $300^{\circ} \mathrm{C}$, whereas the PEDOT:PSS/annealed $\left(400^{\circ} \mathrm{C}\right)$ ITO bilayer exhibited lower sheet resistance of $23.56 \Omega / \otimes$ compared to that of bare ITO film annealed at $400^{\circ} \mathrm{C}$ (Fig. 6). The observed decrease in sheet resistance may be related to the improved film quality and/or significant enhancement in the charge conduction at ITO/PEDOT:PSS interface upon annealing of ITO film at $400^{\circ} \mathrm{C}$.

The hole-only devices (HODs) were fabricated using the structure of PEDOT:PSS interlayer coated onto the pristine or annealed ITO electrode with the device structure: ITO (pristine for HOD - A or annealed at $200^{\circ} \mathrm{C}$ for HOD - B, $300^{\circ} \mathrm{C}$ for HOD - C, and $400^{\circ} \mathrm{C}$ for HOD - D)/PEDOT:PSS/TPD/Al. The TPD has been most widely used hole-transporting layer $(\mathrm{HTL})$ in OLEDs with improved device efficiencies. Figure 7 shows the molecular structures, device structure, and energy level diagram of the materials used in the fabricated HODs. The energy level diagram indicates (i) lower hole injection barrier $\left(\Delta_{h}\right)$ of $0.3 \mathrm{eV}$ at ITO/PEDOT:PSS and $0.5 \mathrm{eV}$ at PEDOT:PSS/TPD interfaces for significantly efficient and dominant hole current, and (ii) the higher electron injection barrier $\left(\Delta_{\mathrm{e}}\right)$ of $2.0 \mathrm{eV}$ at TPD/Al interface for almost negligible electron current in the devices. Figure 8 shows the current density-voltage $(J-V)$ characteristics of the HODs. The HOD - A based on pristine ITO exhibits the on-set of hole injection above $0.5 \mathrm{~V}$ below which the leakage current dominates and hence the hole injection current can barely be extracted [36]. It is also observed that the hole injection on-set is hindered at around 0.5 V for other HODs (B - D) due to the leakage current domination. The hole current density of HOD - $C$ at lower bias voltage is observed to be slightly less $\left(45 \mu \mathrm{A} / \mathrm{cm}^{2}\right.$ at $1 \mathrm{~V}, 0.28 \mathrm{~mA} / \mathrm{cm}^{2}$ at $3 \mathrm{~V}$, and $3.67 \mathrm{~mA} / \mathrm{cm}^{2}$ at $\left.6 \mathrm{~V}\right)$ when compared to that of HOD - A $\left(83 \mu \mathrm{A} / \mathrm{cm}^{2}\right.$ at $1 \mathrm{~V}, 0.28 \mathrm{~mA} / \mathrm{cm}^{2}$ at $3 \mathrm{~V}$, and $2.80 \mathrm{~mA} / \mathrm{cm}^{2}$ at $\left.6 \mathrm{~V}\right)$ and $\mathrm{HOD}-\mathrm{B}\left(97 \mu \mathrm{A} / \mathrm{cm}^{2}\right.$ at $1 \mathrm{~V}$, 
$0.34 \mathrm{~mA} / \mathrm{cm}^{2}$ at $3 \mathrm{~V}$, and $3.24 \mathrm{~mA} / \mathrm{cm}^{2}$ at $6 \mathrm{~V}$ ) without any significant change in hole current density at higher deriving voltages as shown in Fig. 8. The HOD - D exhibited a drastic increase in hole current density $\left(0.7 \mathrm{~mA} / \mathrm{cm}^{2}\right.$ at $1 \mathrm{~V}, 6.52 \mathrm{~mA} / \mathrm{cm}^{2}$ at $3 \mathrm{~V}$, and $38.21 \mathrm{~mA} / \mathrm{cm}^{2}$ at $\left.6 \mathrm{~V}\right)$ when compared to other HODs (A - C). The surface chemical and/or morphological features of ITO film annealed at $400^{\circ} \mathrm{C}$ may play a critical role in favor of improved hole injection and transport through ITO/PEDOT:PSS interface.

The interface barrier potentials of the HODs (A - D) were estimated from the Fowler-Nordheim (F-N) plots $\left(\mathrm{Ln}\left(J / \mathrm{E}^{2}\right)\right.$ verses $\left.1 / \mathrm{E}\right)$ drawn from the $J-V$ characteristics of the devices as shown in the Fig. 9 . The slope of linear region is directly proportional to $\varphi^{3 / 2}$, where $\varphi$ is the barrier potential for charge injection by tunneling at the interface in the devices [37]. The slope of pristine ITO based HOD - A is found to be 6.6 $\times 10^{-4}$ and is increasing as annealing temperature increases upto $300^{\circ} \mathrm{C}\left(10.7 \times 10^{-4}\right.$ for HOD $-\mathrm{B}$ and $16.4 \times 10^{-4}$ for HOD $-C$ ). It is also observed that the slope of HOD - D is drastically decreased to $3.1 \times 10^{-}$ ${ }^{4}$, showing the decreased barrier potential for charge injection in the device. These results reveal that annealing of ITO thin film at higher temperature of $400^{\circ} \mathrm{C}$ under the normal ambient improves the ITO/PEDOT:PSS surface interface properties and lowers the barrier potential for charge injection, resulting in the higher hole current density in the HODs.

In order to examine the effect of annealing of ITO thin film at ITO/PEDOT:PSS interface on the device performance of organic photovoltaic cells (OPVs), we fabricate the OPVs with the device structure of ITO (pristine for device $\mathrm{A}$ or annealed at $200^{\circ} \mathrm{C}$ for device $\mathrm{B}, 300^{\circ} \mathrm{C}$ for device $\mathrm{C}$, and $400^{\circ} \mathrm{C}$ for device D)/PEDOT:PSS (45 nm)/P3HT:PCBM (100 nm)/LiF (1 nm)/Al (120 nm) (Fig. 10). The current density voltage $(J-V)$ characteristics of the devices $(A-D)$ are shown in Fig. 11 and the estimated device parameters are given in the Table 2. The device $A$ with pristine ITO exhibited the low open circuit voltage $\left(V_{o c}\right)$ of $0.28 \mathrm{~V}$ with the short-circuit current density $\left(J_{s c}\right)$ of $6.48 \mathrm{~mA} / \mathrm{cm}^{2}$, fill factor $(F F)$ of 0.26 , and the efficiency $(\eta)$ of $0.48 \%$. It is observed that the $V_{o c}$ is increasing with increasing $F F$ and $\eta$ as the annealing of ITO film increases $\left(V_{o C}=0.36 \mathrm{~V}, F F=0.29\right.$, and $\eta=0.57 \%$ for device $\mathrm{B}\left(200^{\circ} \mathrm{C}\right) ; V_{o c}=0.50 \mathrm{~V}, F F=0.35$, and $\eta=0.60 \%$ for device $\mathrm{C}\left(300^{\circ} \mathrm{C}\right)$; and $V_{o C}=0.54 \mathrm{~V}, F F=0.42$, and $\eta=1.69 \%$ for device $\mathrm{D}\left(400^{\circ} \mathrm{C}\right)$ ), which may be attributed to the fact of decreasing charge trap levels at the PEDOT:PSS/active layer interface due to improved molecular orientation of PEDOT:PSS film upon annealing of ITO film under the normal ambient [38]. It is also observed that the $J_{s c}$ of devices is decreasing upon annealing of ITO film upto $300^{\circ} \mathrm{C}\left(5.30 \mathrm{~mA} / \mathrm{cm}^{2}\right.$ for device $B\left(200^{\circ} \mathrm{C}\right)$ and $3.39 \mathrm{~mA} / \mathrm{cm}^{2}$ for device $\left.\mathrm{C}\left(300^{\circ} \mathrm{C}\right)\right)$, which may be associated with the increasing barrier potential at the annealed ITO/PEDOT:PSS interface. The $J_{s c}$ of device $D$ using annealed ITO film at $400^{\circ} \mathrm{C}$ is drastically increased to $7.40 \mathrm{~mA} / \mathrm{cm}^{2}$ with increased device parameters $\left(V_{o c}=0.54 \mathrm{~V}, F F=0.42\right.$, and $\left.\eta=1.69 \%\right)$ when compared to other devices $(\mathrm{A}-\mathrm{C})$. These results show that annealing of ITO film at high temperature of $400^{\circ} \mathrm{C}$ under the normal ambient may alter the energy levels and/or interface properties of the ITO/PEDOT:PSS interface, enhancing the hole collection/extraction and resulting in the higher efficiency of OPVs. 
Table 2

The estimated device parameters of OPVs using the bilayer structure of PEDOT:PSS layer coated onto pristine or annealed ITO films.

\begin{tabular}{|lllll|}
\hline Device & $\mathrm{J}_{\mathrm{sc}}$ & $\mathrm{V}_{\text {oc }}$ & Fill Factor & $\begin{array}{l}\text { Efficiency } \\
(\%)\end{array}$ \\
\hline A & 6.48 & 0.28 & 0.26 & 0.48 \\
\hline B & 5.30 & 0.36 & 0.29 & 0.57 \\
\hline C & 3.39 & 0.50 & 0.35 & 0.60 \\
\hline D & 7.40 & 0.54 & 0.42 & 1.69 \\
\hline
\end{tabular}

\section{Conclusion}

The annealing of ITO film at $400^{\circ} \mathrm{C}$ reveals higher transparency in the visible region and improves the film quality upon aggregation of native grains into large crystallites, resulting in decreased dislocation density and lattice strain, and leaving the wrinkle kind of surface morphology. The spin coating of PEDOT:PSS film onto the wrinkle kind of surface morphology smoothens the surface and absorbs the UV light significantly. The higher hole current density of the HODs based on ITO annealed (400 $\left.{ }^{\circ} \mathrm{C}\right) / \mathrm{PEDOT}$ :PSS interlayer may be associated with decreased potential barrier at the ITO/PEDOT:PSS interface for hole injection process into the device due to improved interfacial (energy levels and/or surface area) properties. The OPV using the annealed $\left(400^{\circ} \mathrm{C}\right)$ ITO/PEDOT:PSS buffer layer exhibits the efficiency three times higher $(\eta=1.69 \%)$ than that $(\eta=0.48 \%)$ of pristine ITO based device. These results show that the ITO film (annealed at $400^{\circ} \mathrm{C}$ )/PEDOT:PSS interface favors the effective hole injection/extraction process in the devices for the improved performances. The spin coating of PEDOT:PSS layer onto the annealed $\left(400^{\circ} \mathrm{C}\right)$ ITO anodic electrode could be an effective way to improve the device performances of OLEDs and OPVs for the commercial applications.

\section{Credit authorship contribution statement}

Gnyaneshwar Dasi: Data curation, Formal analysis, Investigation, Methodology, Resources, Software, Validation, Visualization, Writing - review \& editing. T. Lavanya: Data curation, Investigation, Methodology, Software, Validation, Visualization, Writing - review \& editing. G. Sathiyan: Data curation, Investigation, Methodology, Resources, Validation, Visualization, Writing - review \& editing. R.K. Gupta: Data curation, Investigation, Methodology, Resources, Software, Validation, Visualization, - review \& editing. A. Garg: Data curation, Investigation, Methodology, Resources, Software, Validation, Visualization, Writing - review \& editing. P. Amaladass: Formal analysis, Methodology, Resources, Software, Validation, Visualization, Writing - review \& editing. K. Thangaraju: Conceptualization, Formal analysis, Investigation, Funding acquisition, Project Administration, Methodology, Resources, Software, Validation, Visualization, Writing - original draft, Writing - review \& editing. 


\section{Declarations}

\section{Declaration of competing interest}

The authors declare that they have no known competing financial interests or personal relationships that could have appeared to influence the work reported in this paper.

\section{Acknowledgement}

The authors acknowledge the financial support from Science and Engineering Research Board (SERB), Department of Science and Technology (DST), New Delhi, India, through a project (SERB/FTP/PS162/2012) to carry out this research work. We thank Center of Excellence (CoE) (TEQIP) and NIT Warangal for providing the research facilities. We also thank the Director of Indian Institute of Technology (IIT Kanpur), for providing the facilities for the fabrication of OPVs and device characterizations.

\section{References}

1. J. C. Deaton, S. C. Switalski, D. Y. Kondakov, R. H. Young, T. D. Pawlik, D. J. Giesen, S. B. Harkins, A. J. M. Miller, S. F. Mickenberg, and J. C. Peters, Journal of the American Chemical Society 132, 9499 (2010).

2. J. Li, T. Nakagawa, J. Macdonald, Q. Zhang, H. Nomura, H. Miyazaki, and C. Adachi, Advanced Materials 25, 3319 (2013).

3. S. J. Yoo, H. J. Yun, I. Kang, K. Thangaraju, S. K. Kwon, and Y. H. Kim, Journal of Materials Chemistry C 1, 2217 (2013).

4. A. C. Arias, M. Granströ, D. S. Thomas, K. Petritsch, and R. H. Friend, Physical Review B 60, 1854 (1999).

5. W. H. Baek, H. Yang, T. S. Yoon, C. J. Kang, H. H. Lee, and Y. S. Kim, Solar Energy Materials and Solar Cells 93, 1263 (2009).

6. K. Thangaraju, J. Kumar, P. Amaladass, A. K. Mohanakrishnan, and V. Narayanan, Applied Physics Letters 89, 082106 (2006).

7. K. Thangaraju, P. Amaladass, K. S. Bharathi, A. K. Mohanakrishnan, V. Narayanan, and J. Kumar, Applied Surface Science 255, 5760 (2009).

8. K. Thangaraju, J. Lee, J. I. Lee, H. Y. Chu, S. O. Kim, M. G. Shin, Y. H. Kim, and K. Soon-Ki, Thin Solid Films 519, 6073 (2011).

9. M. G. Shin, K. Thangaraju, S. O. Kim, J. W. Park, Y. H. Kim, and S. K. Kwon, Organic Electronics 12, 785 (2011).

10. M. C. Hwang, K. Thangaraju, K. H. So, S. C. Shin, S. K. Kwon, and Y. H. Kim, Synthetic Metals 162, 391 (2012).

11. S. O. Kim, K. Thangaraju, S. Jung, W. Lu, S. M. Park, J. Lee, J. I. Lee, H. Y. Chu, Y. H. Kim, and S. K. Kwon, Journal of Nanoscience and Nanotechnology 12, 4375 (2012). 
12. J. He, M. Lu, X. Zhou, J. R. Cao, K. L. Wang, L. S. Liao, Z. B. Deng, X. M. Ding, X. Y. Hou, and S. T. Lee, Thin Solid Films 363, 240 (2000).

13. V. S. Reddy, K. Das, A. Dhar, and S. K. Ray, Semiconductor Science and Technology 21, 1747 (2006).

14. C. C. Wu, C. I. Wu, J. C. Sturm, and A. Kahn, Applied Physics Letters 70, 1348 (1997).

15. S. S. Kim, S. Y. Choi, C. G. Park, and H. W. Jin, Thin Solid Films 347, 155 (1999).

16. D. A. Rider, R. T. Tucker, B. J. Worfolk, K. M. Krause, A. Lalany, M. J. Brett, J. M. Buriak, and K. D. Harris, Nanotechnology 22, 085706 (2011).

17. J. R. Sheats, H. Antoniadis, M. Hueschen, W. Leonard, J. Miller, R. Moon, D. Roitman, and A. Stocking, Science 273, 884 (1996).

18. Y. Yang, E. Westerweele, C. Zhang, P. Smith, and A. J. Heeger, Journal of Applied Physics 77, 694 (1995).

19. E. I. Aminaka, T. Tsutsui, and S. Saito, Journal of Applied Physics 79, 8808 (1996).

20. J. S. Kim, F. Cacialli, A. Cola, G. Gigli, and R. Cingolani, Applied Physics Letters 75, 19 (1999).

21. D. K. Maurya, Microelectronics Journal 38, 76 (2007).

22. B. R. Cho and I. Y. Park, Journal of the Korean Physical Society 53, 19 (2008).

23. Y. N. Kim, H. G. Shin, J. K. Song, D. H. Cho, H. S. Lee, and Y. G. Jung, Journal of Materials Research 20, 1574 (2005).

24. G. Dasi, K. Asokan, and K. Thangaraju, Applied Physics A: Materials Science and Processing 123, 179 (2017).

25. X. D. Dang, M. Dante, and T. Q. Nguyen, Applied Physics Letters 93, 241911 (2008).

26. Z. Su, L. Wang, Y. Li, H. Zhao, B. Chu, and W. Li, Nanoscale Research Letters 7, 1 (2012).

27. S. W. Baek, J. Noh, C. H. Lee, B. Kim, M. K. Seo, and J. Y. Lee, Scientific Reports 3, 1 (2013).

28. M. P. de Jong, L. J. van ljzendoorn, and M. J. A. de Voigt, Applied Physics Letters 77, 2255 (2000).

29. J. Y. Kim, K. Lee, N. E. Coates, D. Moses, T. Q. Nguyen, M. Dante, and A. J. Heeger, Science 317, 222 (2007).

30. Y. D. Glinka, S. H. Lin, L. P. Hwang, and N. H. Tolk, Physical Review B - Condensed Matter and Materials Physics 64, 854211 (2001).

31. B. E. Warren and E. P. Warekois, Acta Metallurgica 3, 473 (1955).

32. G. K. Williamson and W. H. Hall, Acta Metallurgica 1, 22 (1953).

33. T. Ungár, Scripta Materialia 51, 777 (2004).

34. P. Dhamodharan, C. Manoharan, M. Bououdina, R. Venkadachalapathy, and S. Ramalingam, Solar Energy 141, 127 (2017).

35. S. J. Kwon, J. H. Park, and J. G. Park, Physical Review E - Statistical, Nonlinear, and Soft Matter Physics 71, 011604 (2005).

36. M. Castellani, I. Salzmann, P. Bugnon, S. Yu, M. Oehzelt, and N. Koch, Applied Physics A: Materials Science and Processing 97, 1 (2009). 
37. R. H. Fowlder and L. Nordheim, Proceedings of the Royal Society A 125, 5 (2010).

38. N. Koch, A. Elschner, J. P. Rabe, and R. L. Johnson, Advanced Materials 17, 330 (2005).

\section{Figures}

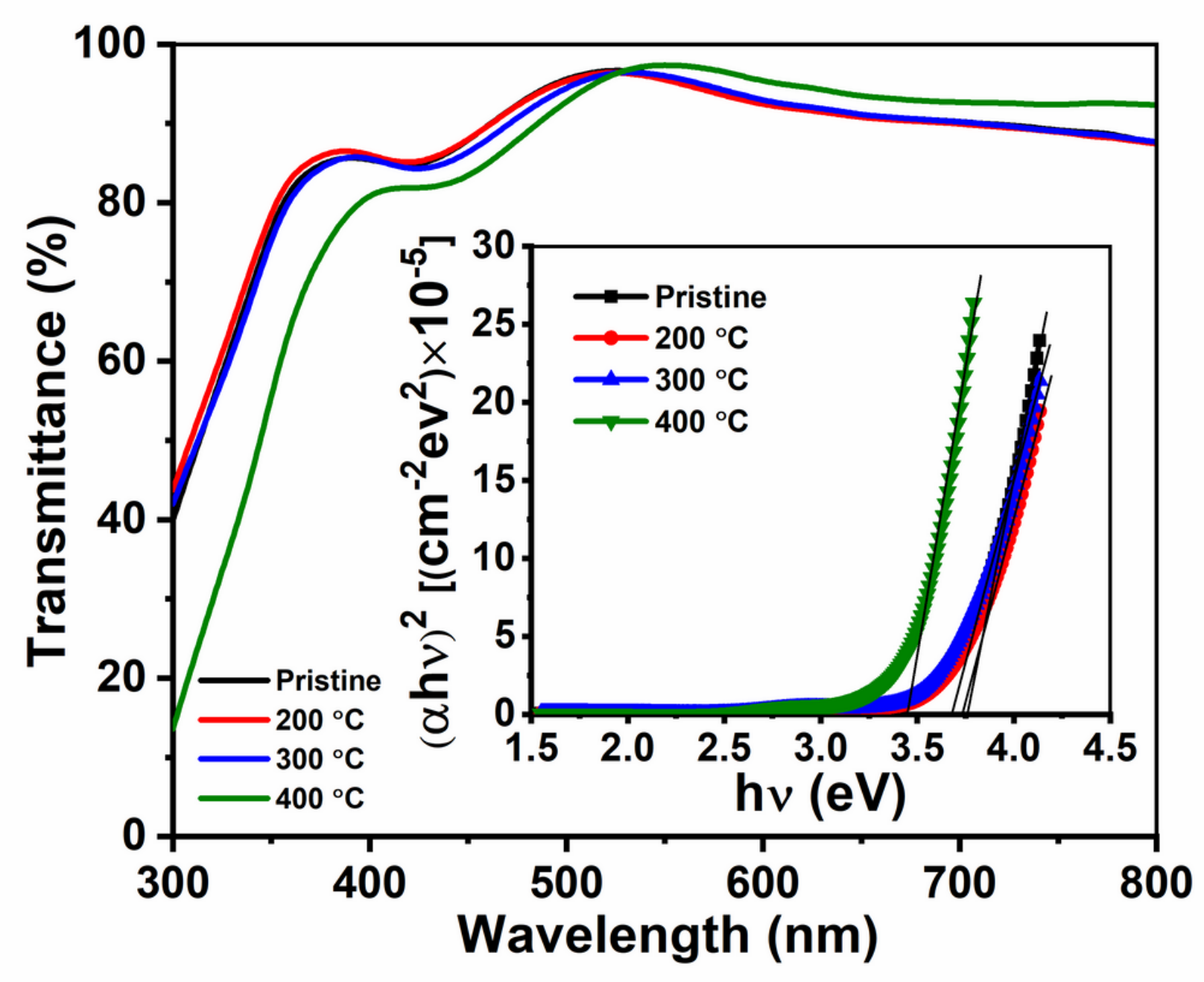

Figure 1

The optical transmittance spectra of the bilayer structure of PEDOT:PSS layer coated onto pristine or annealed $\left(200^{\circ} \mathrm{C}, 300^{\circ} \mathrm{C}\right.$, and $\left.400^{\circ} \mathrm{C}\right)$ ITO films under the normal ambient. Insert shows the dependence of the absorption coefficient on the photon energy, Tauc plots. 


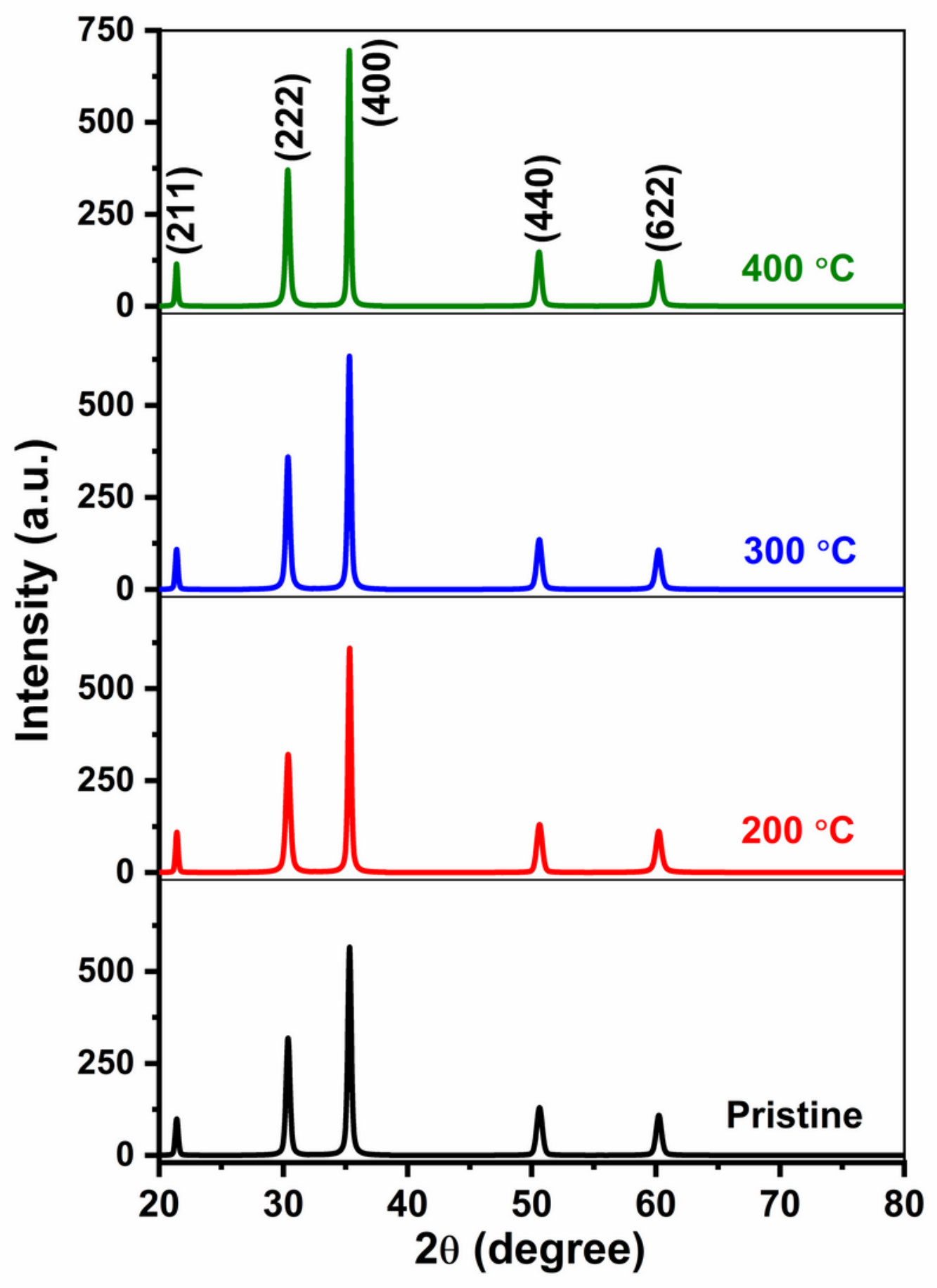

Figure 2

XRD patterns of the bilayer structure of PEDOT:PSS layer coated onto pristine or annealed $\left(200{ }^{\circ} \mathrm{C}, 300{ }^{\circ} \mathrm{C}\right.$, and $400{ }^{\circ} \mathrm{C}$ ) ITO films under the normal ambient. 


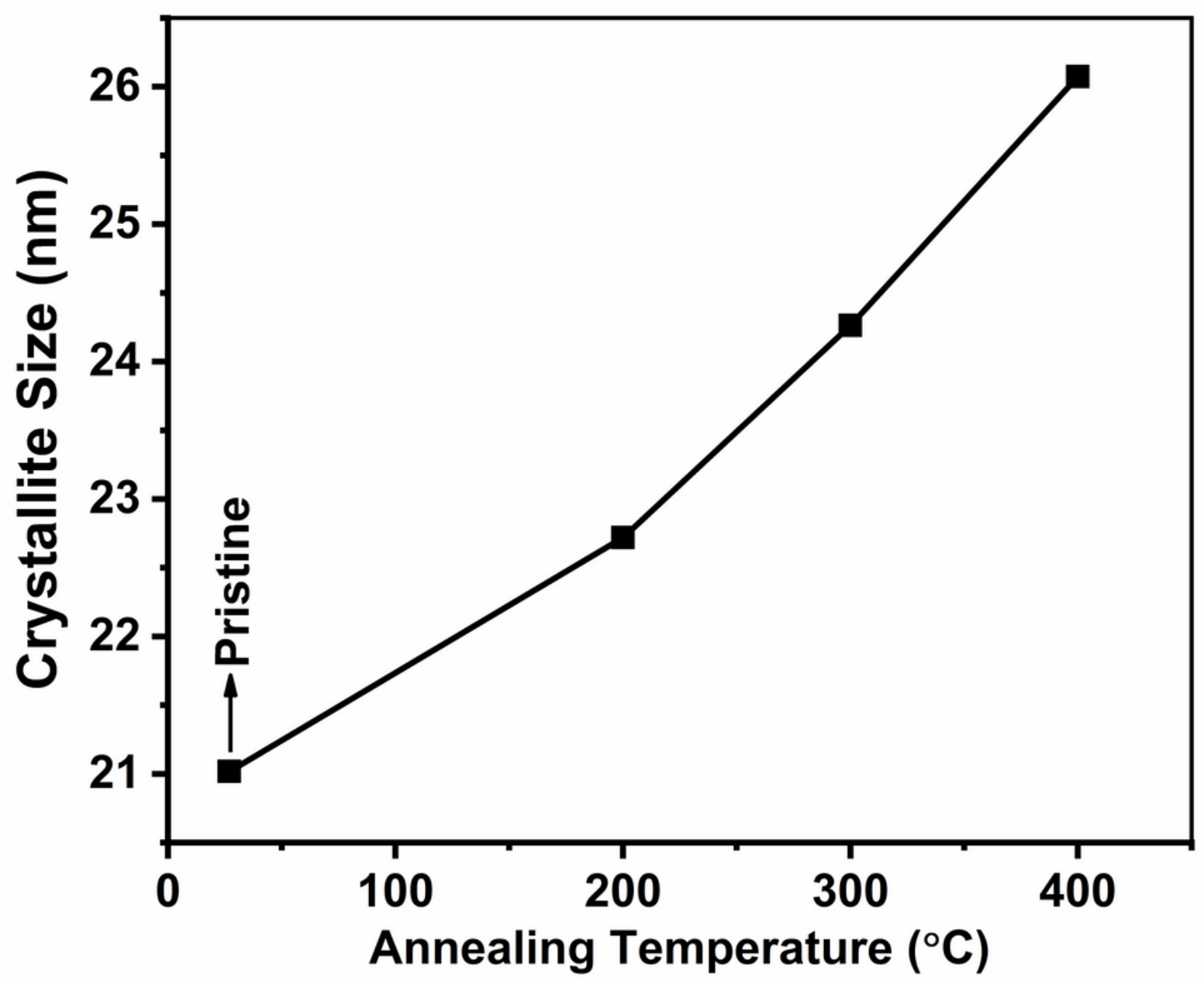

Figure 3

The crystallite size estimated from the XRD data of the bilayer structure of PEDOT:PSS layer coated onto pristine or annealed $\left(200^{\circ} \mathrm{C}, 300^{\circ} \mathrm{C}\right.$, and $\left.400^{\circ} \mathrm{C}\right)$ ITO films under the normal ambient. 

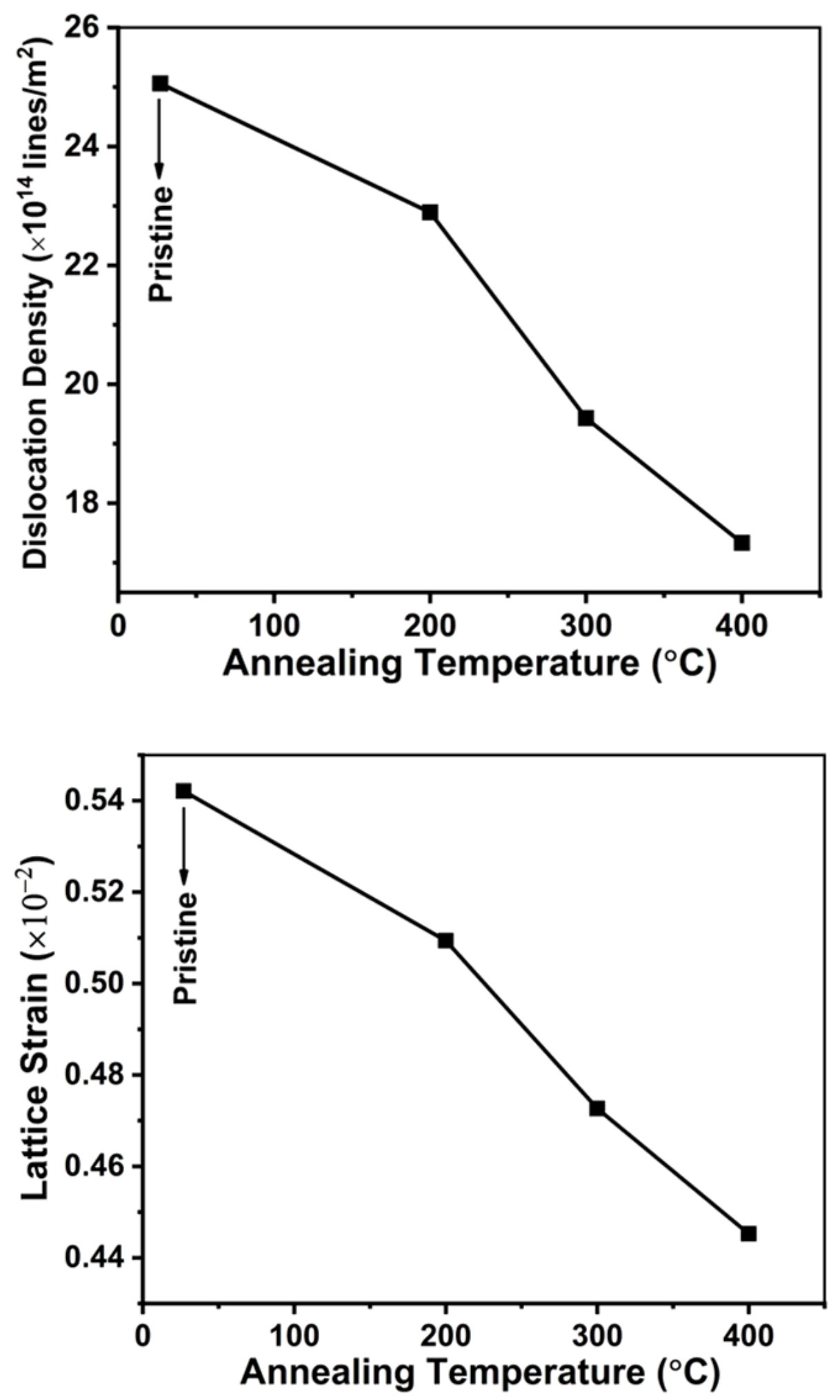

Figure 4

The estimated dislocation density (i) and lattice strain (ii) for the bilayer structure of PEDOT:PSS layer coated onto pristine or annealed $\left(200^{\circ} \mathrm{C}, 300^{\circ} \mathrm{C}\right.$, and $\left.400{ }^{\circ} \mathrm{C}\right)$ ITO films under the normal ambient. 


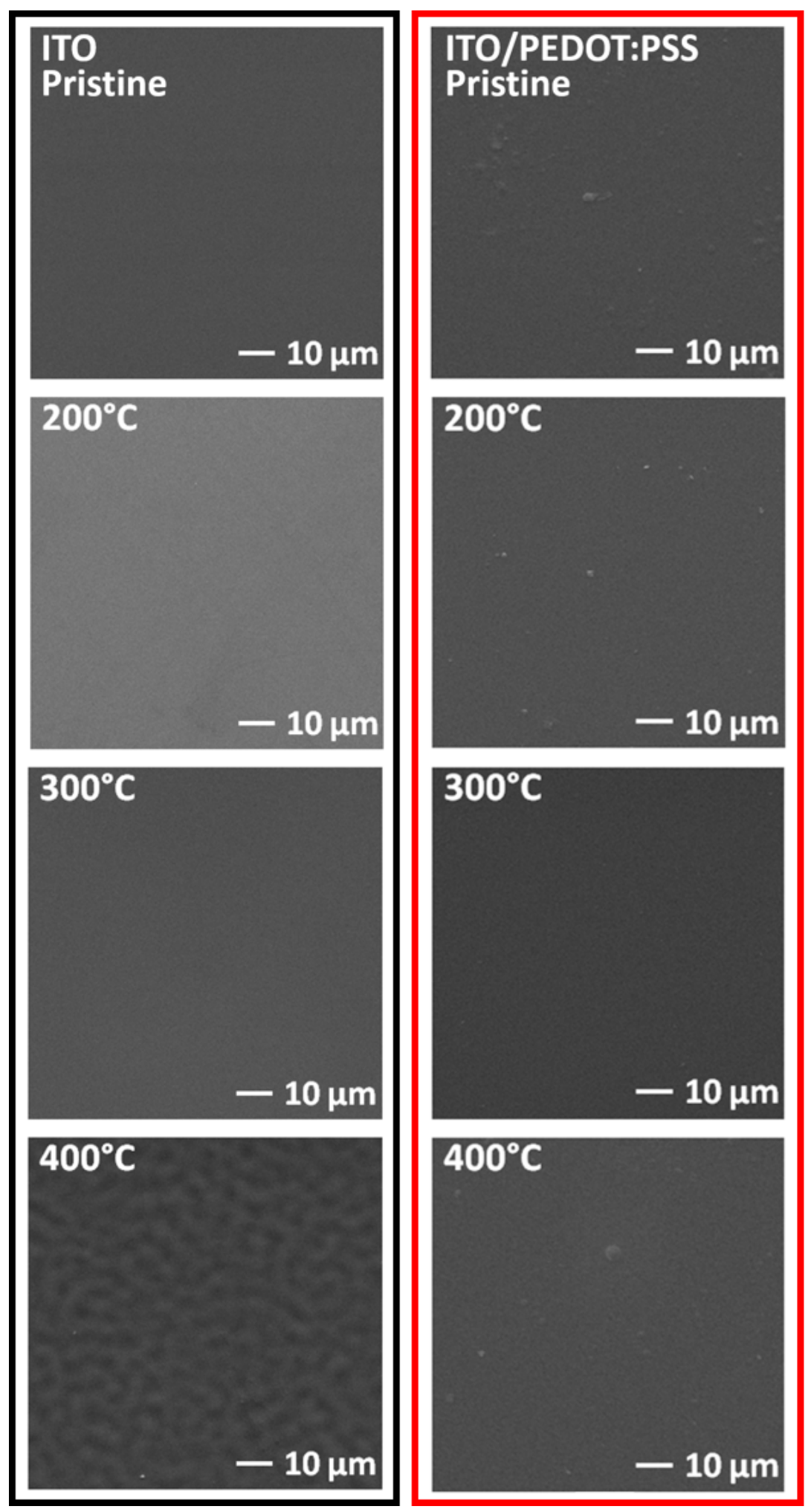

Figure 5

The scanning electron microscopic (SEM) images of PEDOT:PSS layer coated pristine or annealed (200 ${ }^{\circ} \mathrm{C}, 300{ }^{\circ} \mathrm{C}$, and $400{ }^{\circ} \mathrm{C}$ ) ITO films under the normal ambient in comparison with that of bare ITO films (pristine and annealed). 


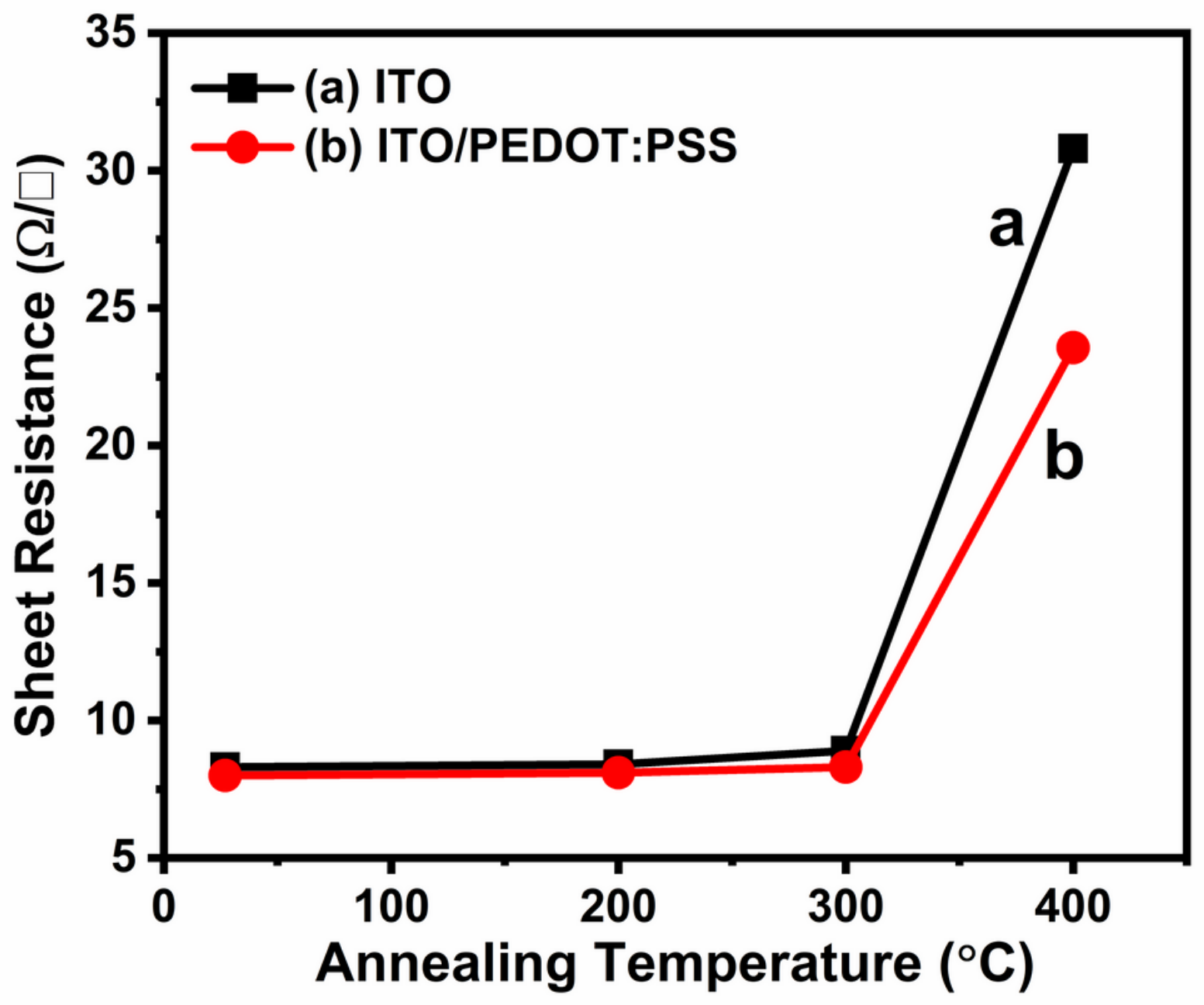

Figure 6

Sheet resistance values of PEDOT:PSS layer coated pristine or annealed $\left(200^{\circ} \mathrm{C}, 300^{\circ} \mathrm{C}\right.$, and $\left.400{ }^{\circ} \mathrm{C}\right)$ ITO films under the normal ambient in comparison with that of bare ITO films (pristine and annealed). 
(a)

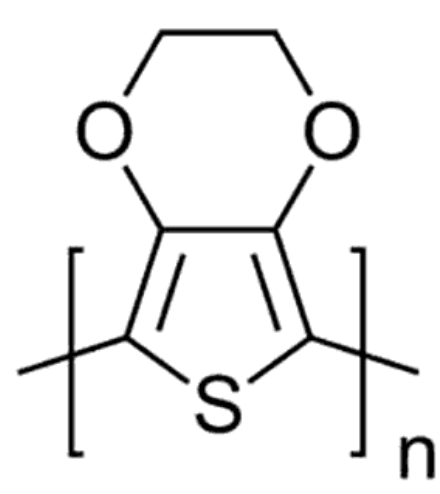

PEDOT

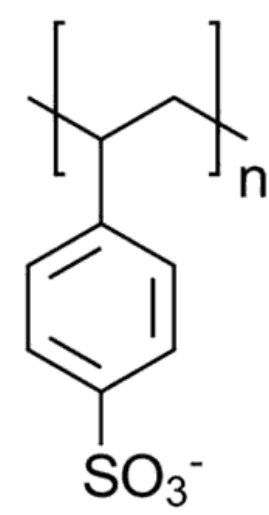

PSS

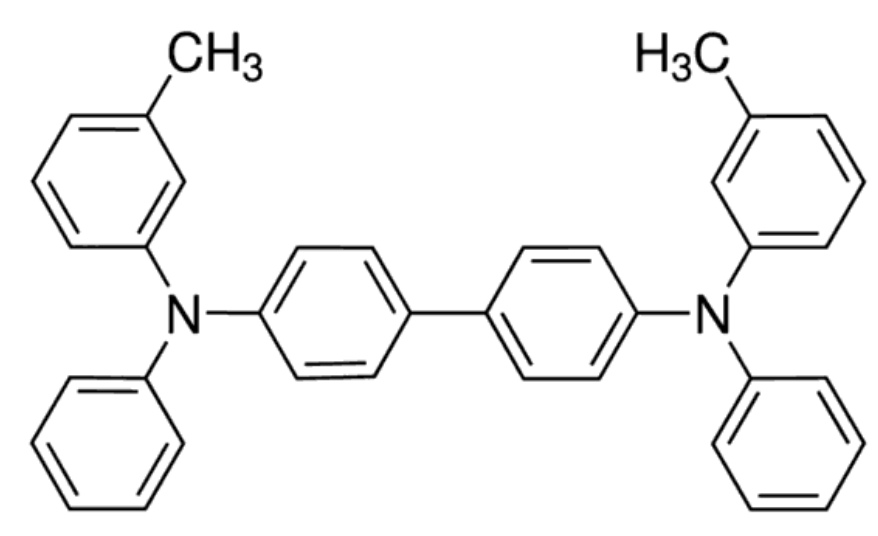

TPD

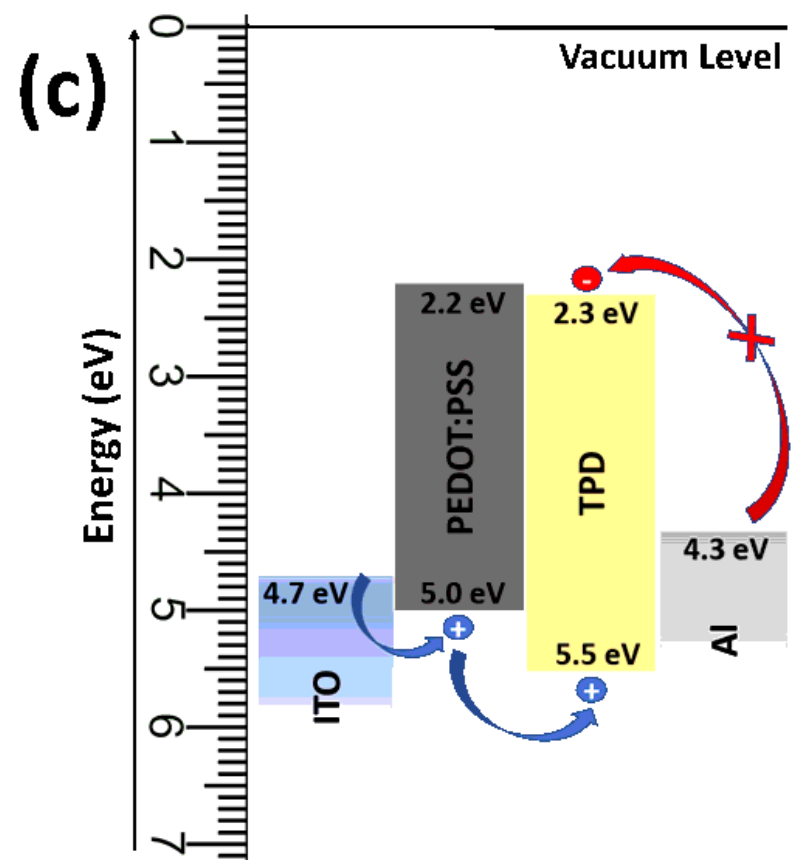

Figure 7

The molecular structures and energy level diagram of the materials used in the hole-only devices (HODs) and its device structure. 


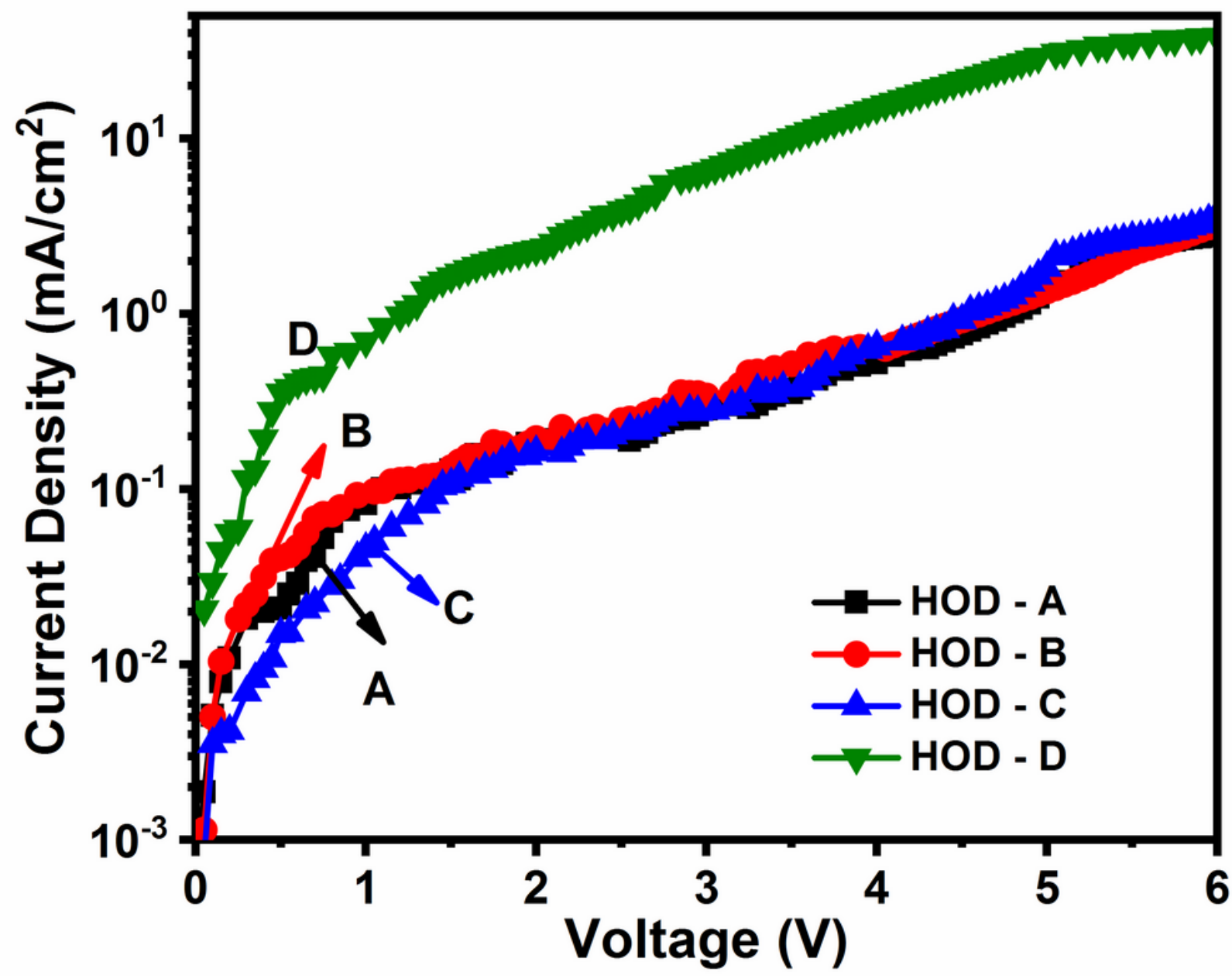

Figure 8

The current density-voltage $(J-V)$ characteristics of the HODs using the bilayer structure of PEDOT:PSS layer coated onto pristine (HOD - A) or annealed (at $200{ }^{\circ} \mathrm{C}$ for HOD - B, $300{ }^{\circ} \mathrm{C}$ for HOD - C, and $400{ }^{\circ} \mathrm{C}$ for HOD - D) ITO anodic films under the normal ambient. 


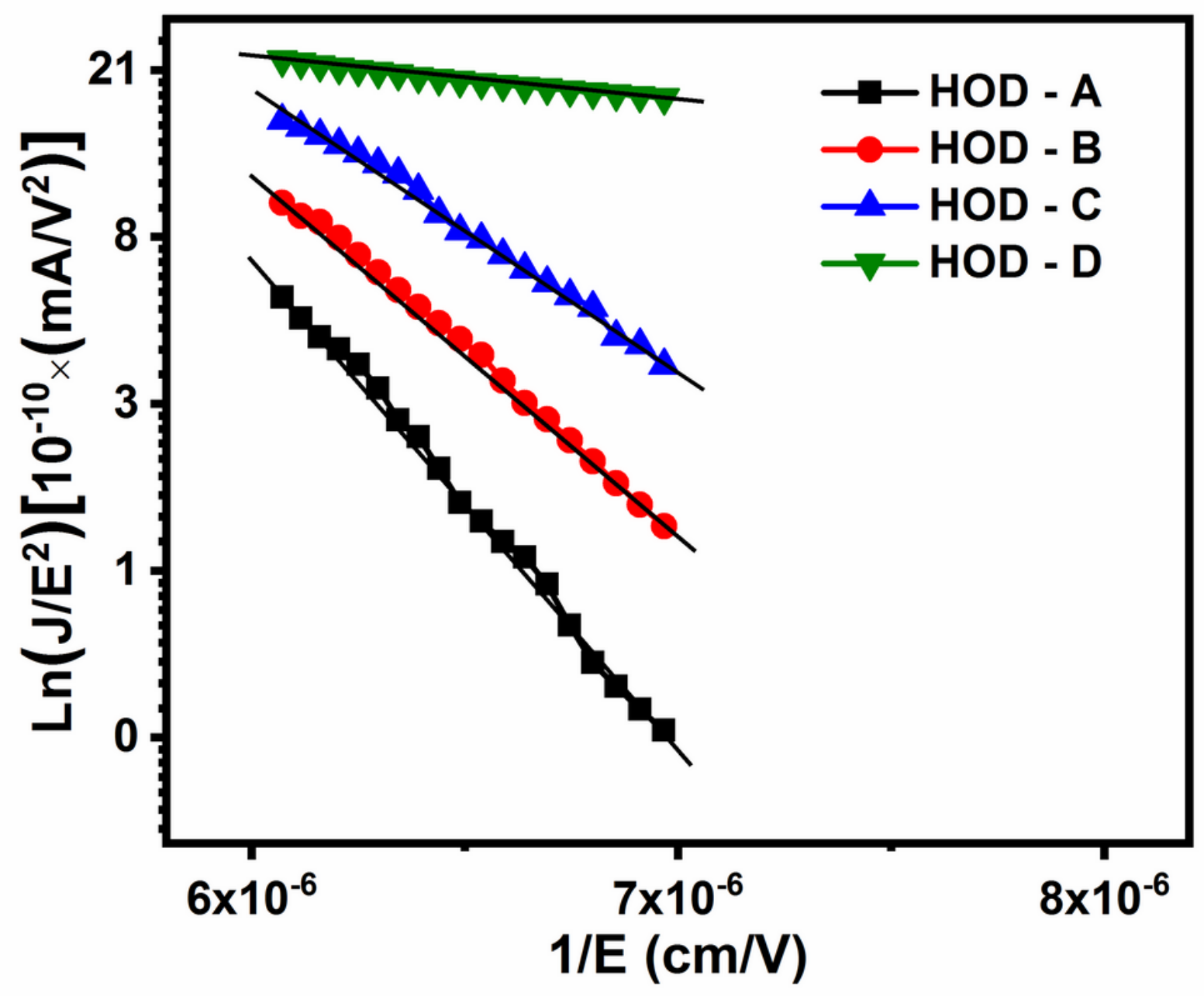

Figure 9

The Fowler-Nordheim (F-N) tunneling plots extracted from the J-V characteristics of the HODs using the bilayer structure of PEDOT:PSS layer coated onto pristine (HOD - A) or annealed (at $200{ }^{\circ} \mathrm{C}$ for HOD - B, $300^{\circ} \mathrm{C}$ for HOD - C, and $400{ }^{\circ} \mathrm{C}$ for HOD - D) ITO anodic films under the normal ambient. 


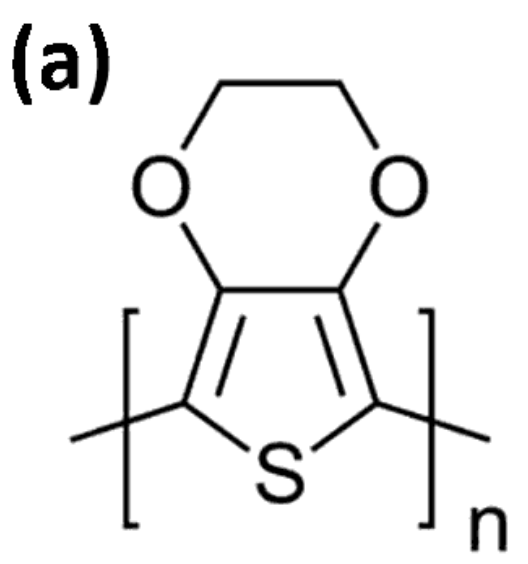

PEDOT

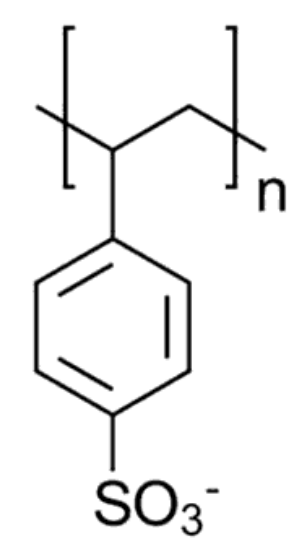

PSS

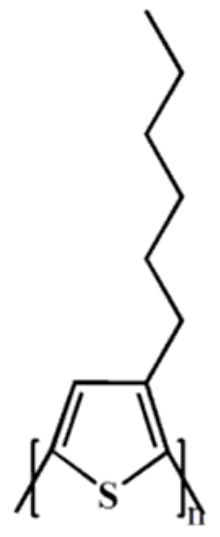

P3HT

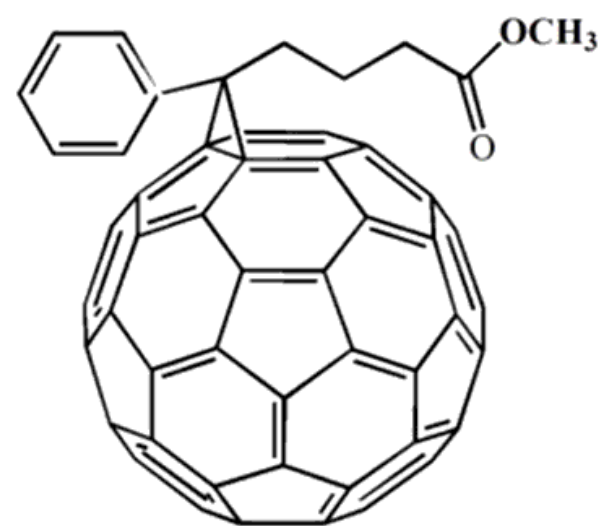

PCBM
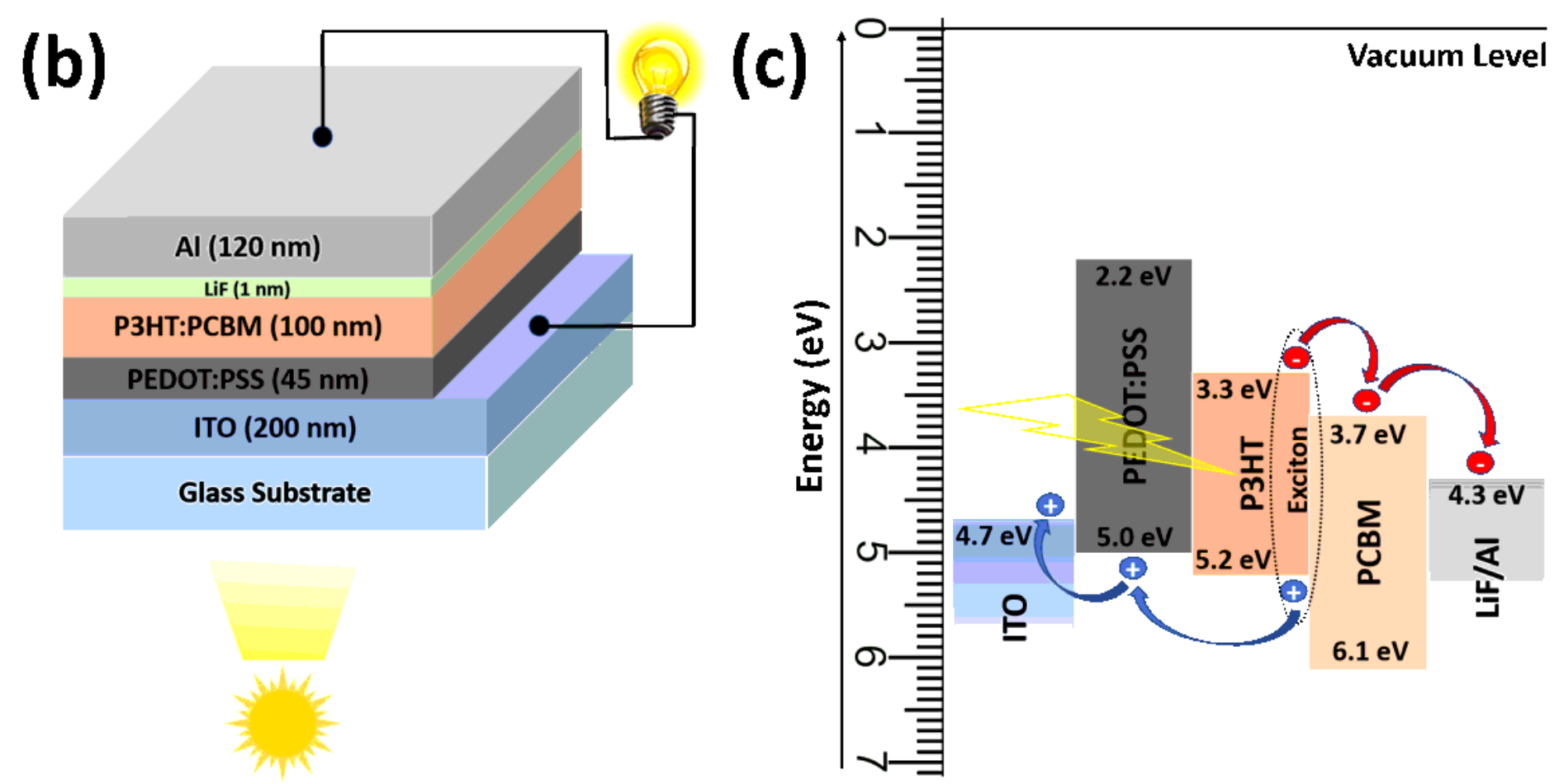

Figure 10

The molecular structures and energy level diagram of the materials used in the organic photovoltaic cells (OPVs) and its device structure. 


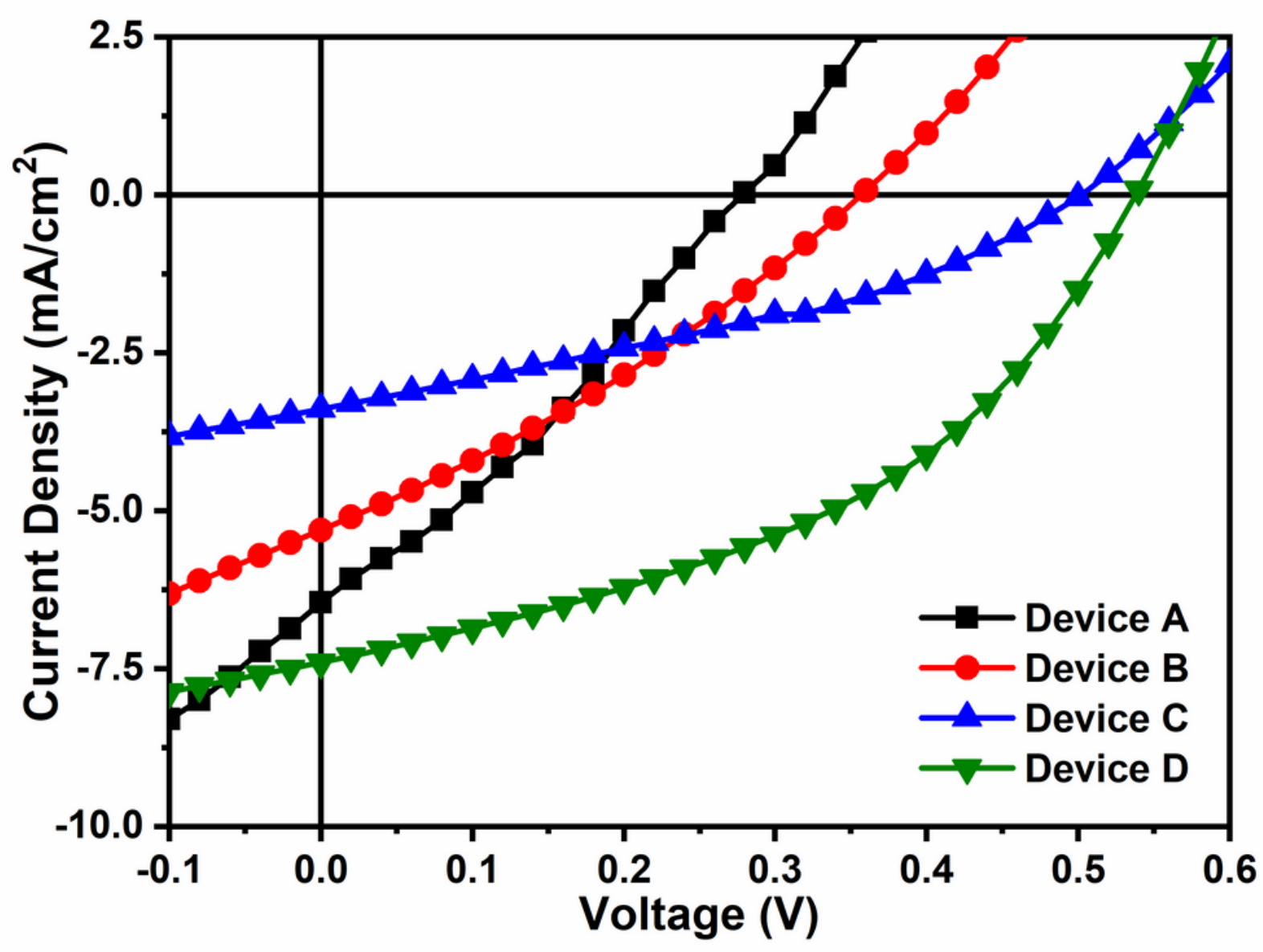

Figure 11

The current density-voltage $(\mathrm{J}-\mathrm{V})$ characteristics of the OPVs using the bilayer structure of PEDOT:PSS layer coated onto pristine (Device A) or annealed (at $200{ }^{\circ} \mathrm{C}$ for Device $\mathrm{B}, 300^{\circ} \mathrm{C}$ for Device $\mathrm{C}$, and $400{ }^{\circ} \mathrm{C}$ for Device D) ITO anodic films under the normal ambient. 